\title{
Wet Oxidation of Formaldehyde with Heterogeneous Catalytic Materials
}

\author{
Mirella Gutiérrez-Arzaluz, Miguel Torres-Rodríguez, Violeta Mugica-Alvarez, Julia Aguilar-Pliego, \\ and Mario A. Romero-Romo
}

\begin{abstract}
This work addresses the activity of the catalytic performance of $\mathrm{Pt}$ and $\mathrm{Ce}-\mathrm{Mn}$-based materials, during the catalytic wet formaldehyde oxidation reaction at ppm concentrations. The comparison of Pt supported in alumina vs. Ce-Mn-based catalysts is presented. The total conversion was $80 \%$ with $\mathrm{Pt} / \mathrm{Al}_{2} \mathrm{O}_{3}$ at $80^{\circ} \mathrm{C}$, which turned out to be more effective in removing the organic pollutant compared with the mixed oxide. By-products formation such as acetic and oxalic acids was determined along with carbonaceous deposits.
\end{abstract}

Index Terms-Catalytic wet oxidation, formaldehyde removal, oxidation, $\mathrm{Pt}$ and $\mathrm{Ce}-\mathrm{Mn}$ catalysts, batch reactor.

\section{INTRODUCTION}

Catalytic wet oxidation processes are three-phase reactions that are somewhat difficult to operate: therefore, they are not technologically ready for commercial application. Presently, it is widely recognized that catalytic wet air oxidation (CWAO) needs further development to become a commercial option, economically viable and environmentally responsible, capable of removing the organic waste generated elsewhere and increasing the possibility to face emerging problems in treating toxic wastewater.

The wet air oxidation (WAO) processes degrade organic pollutants dissolved in water, either partially through an oxidizing agent in biodegradable products, or fully mineralizing them into harmless inorganic compounds, such as $\mathrm{CO}_{2}, \mathrm{H}_{2} \mathrm{O}$ and inorganic salts, which remain in the liquid phase [1].

Compared to wet air oxidation (WAO) technology, the catalyst present in the catalytic wet air oxidation (CWAO) brings in smaller energy requirements [1]; also, there are advantages coupled, since greater oxidation conversion is attained. Consequently, less severe conditions can be used to reduce the chemical oxygen demand, as in this process the organic compounds are oxidized to inorganic usable by-products such as $\mathrm{CO}_{2}$ and $\mathrm{H}_{2} \mathrm{O}$.

Formaldehyde (HCHO) is an important environmental pollutant, widely known for its adverse health effects [2]. It

Manuscript received March 20, 2015; revised June 10, 2015. This work was supported by the Universidad Autónoma Metropolitana.

Mirella Gutiérrez-Arzaluz, Miguel Torres-Rodríguez, Violeta Mugica-Alvarez, and Julia Aguilar-Pliego are with the Basic Sciences Department at Universidad Autónoma Metropolitana Azcapotzalco, México D.F. Av. San Pablo 180, 02200, México (e-mail: gam@correo.azc.uam.mx, trm@correo.azc.uam.mx, vma@correo.azc.uam.mx apj@correo.azc.uam.mx).

Mario A. Romero-Romo is with the Materials Department at the Universidad Autónoma Metropolitana Azcapotzalco, México (e-mail: mmrr@correo.azc.uam.mx). has been chosen as model (molecule) pollutant in the wet catalytic oxidation reaction. This work proposes the use of two catalyst types: one based on a noble metal supported on $\alpha-\mathrm{Al}_{2} \mathrm{O}_{3}$ that is active to the oxidation of refractory compounds and another based on metal oxides, which is more resistant to fouling, despite its lower activity.

\section{EXPERIMENTAL METHODS}

The Ce-Mn mixed oxides-based catalysts were prepared through co-precipitation, under controlled additions of the precursor solution containing an excess basic agent $\left(\mathrm{NH}_{4} \mathrm{OH}\right.$ $30 \%$ weight), followed by calcination at $350^{\circ} \mathrm{C}$, as reported in previous works [3]. Also, samples of commercial alumina impregnated with $\mathrm{Pt}$ by means of the incipient wetness impregnation with $\mathrm{Pt}$ precursor dissolution to obtain a $1 \%$ weight metal load, were prepared here. The actual support used to prepare this catalyst was a commercial sample $\left(\alpha-\mathrm{Al}_{2} \mathrm{O}_{3}\right.$ powder, Sigma-Aldrich). The hexachloroplatinic acid hydrate $\left(\mathrm{H}_{2} \mathrm{PtCl}_{6} \cdot x \mathrm{H}_{2} \mathrm{O}\right.$, Sigma-Aldrich $99.9 \%$, with a platinum content of $38-41 \%$ ) was used as Pt precursor. After drying the powder for about 24 hours at room temperature, the reduction to metal was effected at $350^{\circ} \mathrm{C}$ in $\mathrm{H}_{2}$ atmosphere for two hours before the sample was heat treated with $\mathrm{N}_{2}$ gas, also at $350^{\circ} \mathrm{C}$ for two hours.

The samples were characterized using different techniques, like powder XRD on a Phillips diffractometer X-expert using $\mathrm{Cu} \mathrm{K} \alpha$ radiation, scanning $2 \theta$ from 5 to $80^{\circ}$. Surface topography and elemental composition were established by means of SEM/EDS in a LEO 440 microscope with secondary electrons and EDS detectors. Also, FTIR was carried out in a VARIAN spectrophotometer model 3600 in the IR region with wavelengths in the mid-infrared (between 500 and 4000 $\mathrm{cm}^{-1}$ ), finely grinding the samples in an agate mortar. Texture measurements like the specific surface area, pore diameter and volume, were performed with a Micromeritics ASAP 2020 equipment, using $\mathrm{N}_{2}$ physisorption to obtain highly detailed information on textural properties of the solids manufactured.

The activity of the catalytic systems was studied during catalytic wet formaldehyde oxidation (CWO) reaction at ppm concentrations. The tests were conducted in a conventional stainless steel batch reactor (commercial autoclave Parr Reactor), for the liquid phase, using pure oxygen (PRAXAIR, $99.6 \%$ purity) as an oxidizing agent at $80^{\circ} \mathrm{C}$ reaction temperature; the initial formaldehyde concentration was 200 or $1000 \mathrm{ppm}$. The ratio: catalyst mass to reaction volume was $2.38 \mathrm{~g} \mathrm{l}^{-1}$; testing was carried out at two different oxygen pressures, namely, 40 and 100 psi (2.76 or 6.89 bar). The 
catalytic HCHO oxidation test was studied during four hours. The reaction progress was monitored by gas chromatography using an HP 5890 series II Plus chromatograph with flame ionization detector (FID) and GC Chem Station software ((C) Agilent Technologies), along with a capillary column HP PLOT Q 30m long and $0.32 \mathrm{~mm}$ in diameter, suitable for separating organic acids and formaldehyde of low molecular weight. The $\mathrm{CO}_{2}$ was determined through the classical $\mathrm{NaOH}$ $0.1 \mathrm{M}$ method.

\section{RESULTS}

\section{A. Characterization}

\section{1) Specific surface area measurements (BET)}

The specific surface area, pore diameter and pore volume measured, are reported in Table I. The values obtained for surface area of the Ce-Mn mixed oxides were $85-130 \mathrm{~m}^{2} \mathrm{~g}^{-1}$, which are within the order of magnitude reported in the literature [4]-[6]. However, for the system $\mathrm{Pt} / \mathrm{Al}_{2} \mathrm{O}_{3}$, low surface area $\left(28.55 \mathrm{~m}^{2} \mathrm{~g}^{-1}\right)$ values were obtained due to the low surface area of the commercial support ( $\alpha$-alumina) [7]-[9].

TABLE I: RESULTS OF N2 ADSORPTION-DESORPTION ANALYSIS

\begin{tabular}{cccc}
\hline \hline Sample & $\begin{array}{c}\text { BET } \\
\left(\mathbf{m}^{\mathbf{2}} \mathbf{g}^{-\mathbf{1}}\right)\end{array}$ & Pore Diameter $(\AA)$ & $\begin{array}{c}\text { Pore Volume } \\
\left(\mathbf{c m}^{\mathbf{3}} \mathbf{g}^{\mathbf{- 1}}\right)\end{array}$ \\
\hline $\mathrm{Ce}-\mathrm{Mn}$ & 129.93 & 27.65 & 0.088 \\
$\mathrm{Pt} / \mathrm{Al}_{2} \mathrm{O}_{3}$ & 28.55 & 241.62 & 0.184 \\
\hline \hline
\end{tabular}

\section{2) X-ray diffraction $(X R D)$}

Fig. 1 shows the XRD patterns recorded from the Ce-Mn sample calcined at $350^{\circ} \mathrm{C}$. The diffractograms were compared with the ICDD data base to identify the phases (i.e. $\mathrm{CeO}_{2}$ (JCDS 34-0394)). The samples exhibited fluorite-type face centered cubic structure; the fact that the diffraction pattern is slightly shifted respect to the ceria pattern, is because the Ce-Mn mixed oxide lattice parameters are different with respect to pure oxides, thus suggesting that the manganese ions are likely to be incorporated within the cerium oxide lattice, probably leading to formation of solid solutions between the manganese and cerium oxides; the $\mathrm{Mn}^{4+}$ ionic radius $(0.053 \mathrm{~nm})$ is smaller than that of the $\mathrm{Ce}^{4+}$ ion $(0.094 \mathrm{~nm})$, which is in agreement with the data reported in the literature [10]-[12].

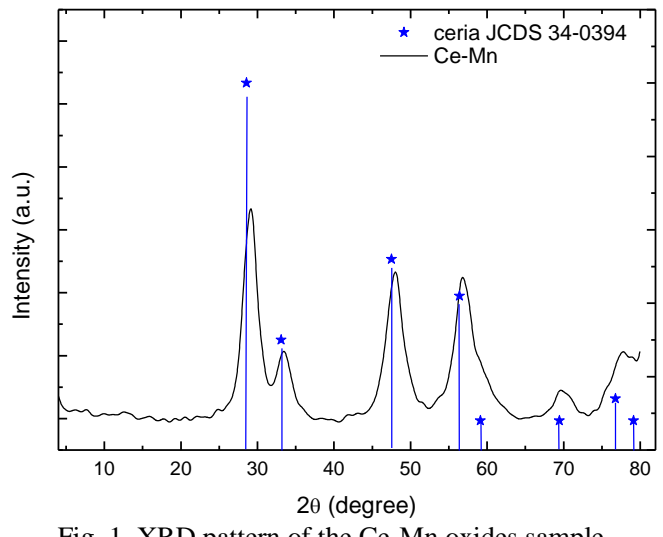

Fig. 1. XRD pattern of the Ce-Mn oxides sample.

Fig. 2 shows the $\mathrm{Pt} / \mathrm{Al}_{2} \mathrm{O}_{3} \mathrm{XRD}$ diffractogram and that of the $\alpha-\mathrm{Al}_{2} \mathrm{O}_{3}$ commercial support. After the Pt addition, the overall appearance of the characteristic peaks suggests that the crystallinity is not affected. The presence of Pt can be corroborated with the peaks that appeared at $40^{\circ}$ and $46^{\circ} 2 \theta$, which show that the platinum has been poorly dispersed on the support and distributed in crystallites of considerable size.

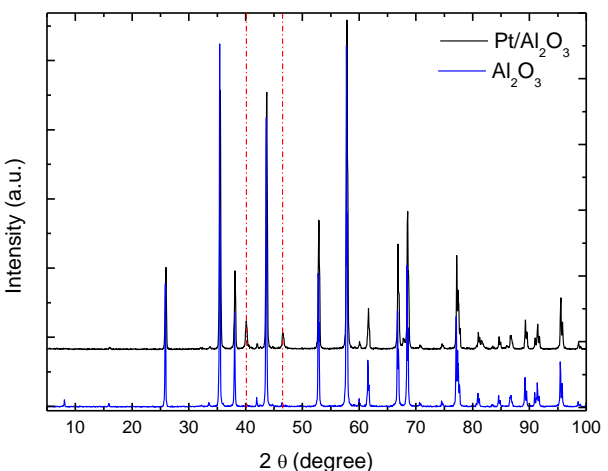

Fig. 2. XRD patterns of the samples $\mathrm{Pt} / \mathrm{Al}_{2} \mathrm{O}_{3}$ and $\mathrm{Al}_{2} \mathrm{O}_{3}$.

\section{3) Scanning electron microscopy (SEM/EDS)}

Fig. 3(a) shows the morphological features of the Ce-Mn sample as determined through secondary electron imaging, that reveals an aggregation of irregular shapeless particles. Fig. 3(b) presents a SEM/EDS image that confirms the presence of $\mathrm{Ce}$ and $\mathrm{Mn}$ in the samples. The images presented in Fig. 3(c) and $d$ are elemental mappings of the metals distributed over the sample: Ce can be identified by the purple color (Fig. 3(c) ) and Mn by orange (Fig. 3(d) ), respectively.

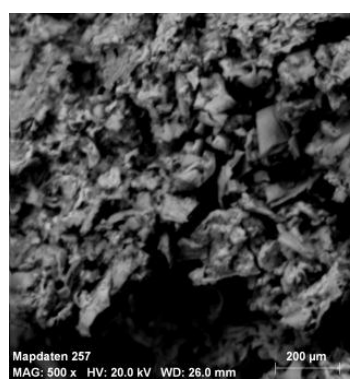

(a)

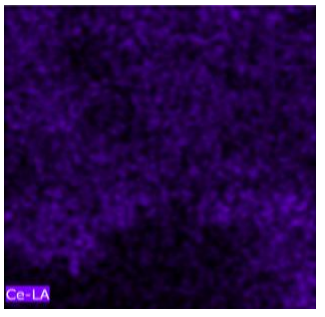

(c)

C-K, Mn-KA, Ce-LA, Date:2/26/2009 1:04:56 PM (d)

Fig. 3. Micrographs of the sample Ce-Mn. (a) SEM Ce-Mn. (b) Ce-Mn mapping. (c) Ce mapping. (d) Mn mapping.

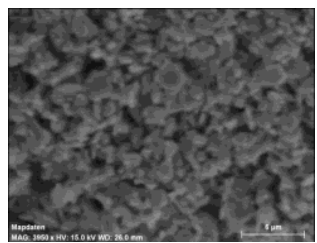

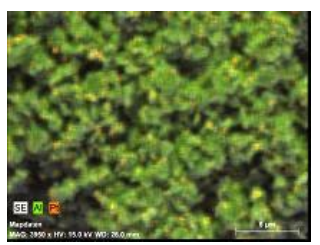

(b)
Fig. 4. (a) SEM micrographs of the sample $\mathrm{Al}_{2} \mathrm{O}_{3}$. (b) SEM/EDS of the $\mathrm{Pt} / \mathrm{Al}_{2} \mathrm{O}_{3}$ 
Fig. 4(a) is also a SEM secondary electron image revealing aggregation of alumina particles, although they are shapeless. The mapping in Fig. 4(b) reveals that the Pt is distributed homogeneously over the surface of the alumina.

\section{B. Catalytic Wet Formaldehyde Oxidation}

\section{1) $\mathrm{Pt} / \mathrm{Al}_{2} \mathrm{O}_{3}$ catalytic test}

For the elimination of formaldehyde with an initial 200 ppm concentration, tested at two different oxygen pressures, namely 40 and $100 \mathrm{psi}$. After four reaction hours at $80^{\circ} \mathrm{C}$, the $\mathrm{HCOH}$ conversion was in both cases about $80 \%$. From Fig. 5, it can be inferred that the greater the oxidizing agent pressure, the more stimulated is the pollutant oxidation initial velocity, as indicated by the greater slope of the curve corresponding to 100 psi pressure. Fig. 5 shows a comparison of the plots indicating that for $50 \%$ formaldehyde conversion, it required twice as much time when using 40 psi pressure compared to $100 \mathrm{psi}$. The increase in the initial reaction rate is associated with a greater amount of dissolved oxygen in the aqueous phase, at $100 \mathrm{psi}$, which actually means an increased oxidation rate of the organic matter [8].

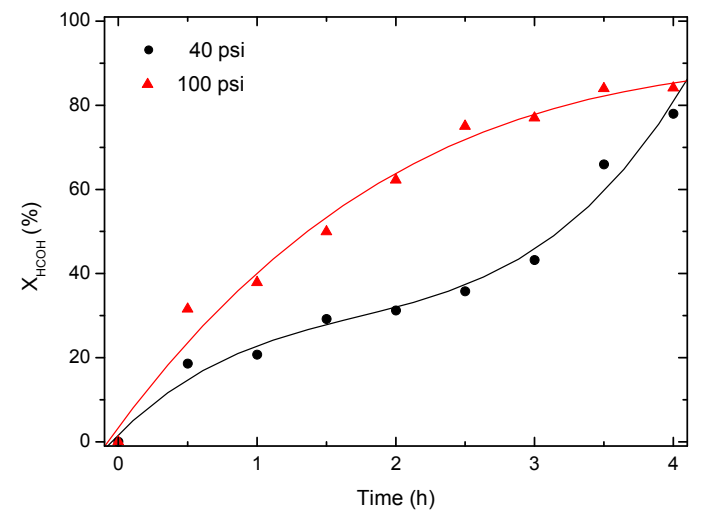

Fig. 5. $\mathrm{HCOH}$ conversion with $\mathrm{Pt} / \mathrm{Al}_{2} \mathrm{O}_{3}$ catalyst a 40 and $100 \mathrm{psi}$ of $\mathrm{O}_{2}$.

Fig. 6 shows that platinum incorporation on the commercial alumina had a favorable effect, because the formaldehyde conversion was twice that observed in the test reaction performed without $\mathrm{Pt}$, also on a commercial alumina powder.

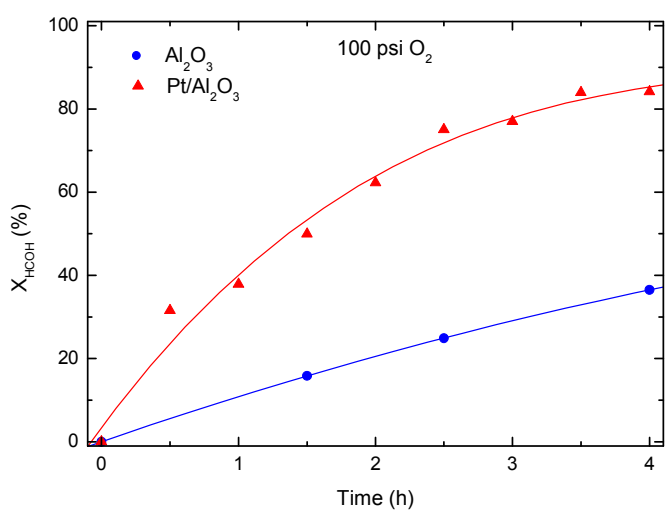

Fig. 6. $\mathrm{HCOH}$ conversion with $\mathrm{Pt} / \mathrm{Al}_{2} \mathrm{O}_{3}$ catalyst and $\mathrm{Al}_{2} \mathrm{O}_{3}$.

During formaldehyde removal it was observed the presence of secondary reaction products such as oxalic acid and acetic acid, though their concentrations were different in both tests, namely at 40 and 100 psi $\mathrm{O}_{2}$, over $80 \mathrm{ppm}$ for oxalic acid, and slightly more than $60 \mathrm{ppm}$ for acetic acid, see
Fig. 7. Thus, formation of these products through formaldehyde oxidation is not dependent on the amount of oxygen present in the reaction. Therefore, it is important to study the dependence on temperature of the formation of these products, since according to Silva et al. [8], the temperature is a key factor in the formaldehyde CWO. It should be noted that in addition to these products in the liquid phase, there were other solid products present, like carbonaceous deposits that were not quantified. Also in the gas phase there was unwanted $\mathrm{CO}_{2}$, among others. The concentration of these other products is modified by the amount of oxygen present: hence, it would be important to elucidate whether this would correspond to $\mathrm{HCOH}$ mineralization.

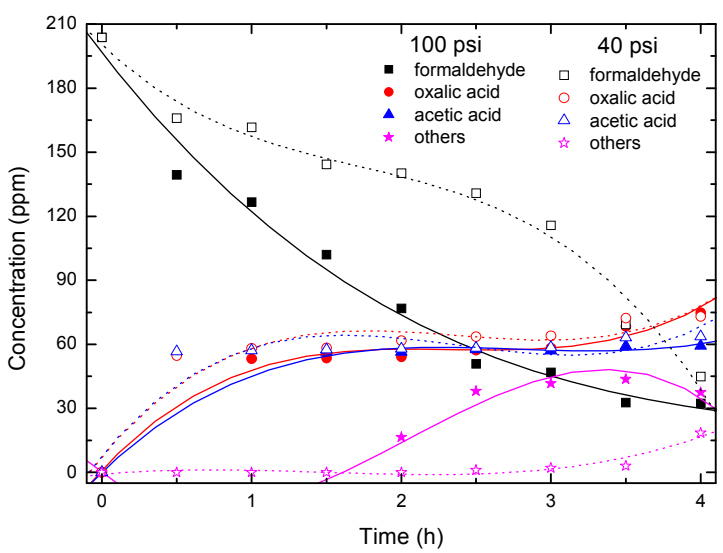

Fig. 7. Concentration of different species as a function of oxidizing agent pressure: 40 and $100 \mathrm{psi}_{2}$.

Besides the effect of oxygen pressure, the effect of initial concentration of formaldehyde, 200 to $1000 \mathrm{ppm}$, was also studied. Fig. 8, clearly shows that most of the pollutant is eliminated when there is less of it in the middle of the reaction, since according to other authors, when working with high concentrations of pollutant and mild reaction conditions (around $90^{\circ} \mathrm{C}$ and 5 bar $\mathrm{O}_{2}$ ), the catalyst exhibited loss of activity after the first minutes of reaction [13]-[16], because the active surface is mostly covered by adsorbed formaldehyde.

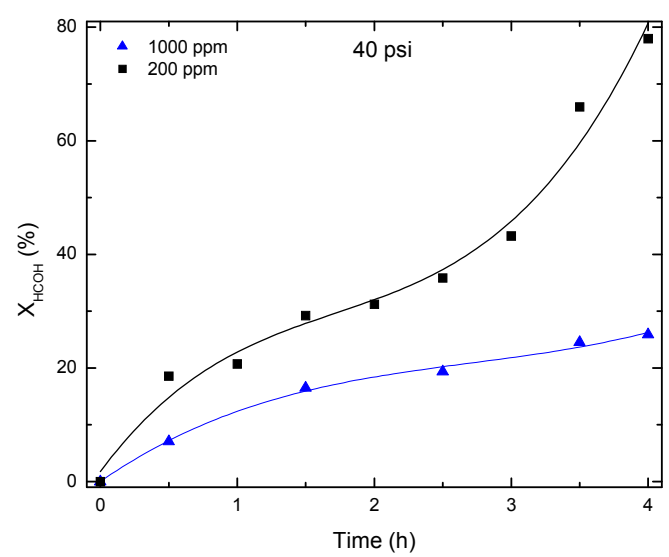

Fig. 8. Conversion rate at two different initial concentrations, 200 and1000 $\mathrm{ppm}$ as a function of formaldehyde oxidation time.

Some authors [14]-[16], reported this behavior and explained it on consideration of the large sensitivity that the contaminant's conversion displays as a function of the relationship between its concentration and the catalyst's mass, 
which is typical of competitive reactant adsorption in heterogeneous catalytic processes. In addition, it is proposed that the catalyst may undergo a rapid and strong deactivation by formation of carbonaceous deposits, which are irreversibly adsorbed on the surface of the catalyst and, as expected, on its active centers.

In this work, the formation of carbonaceous deposits was identified by FTIR analysis that ratified a considerable increase in the intensities of some characteristic bands in the region $1700-1000 \mathrm{~cm}^{-1}$. The bands are difficult to allocate to they occurred in the region of the water fingerprint as a result of moisture in the atmosphere, refer to Fig. 9. These bands overlap considerably with those of some hydrocarbon or carbon compounds. Reduction of the catalyst at $350^{\circ} \mathrm{C}$ leads to high values of dispersed platinum which induces a significant formation of carbonate species, as Mikulov et al. (2007) [17] reported.

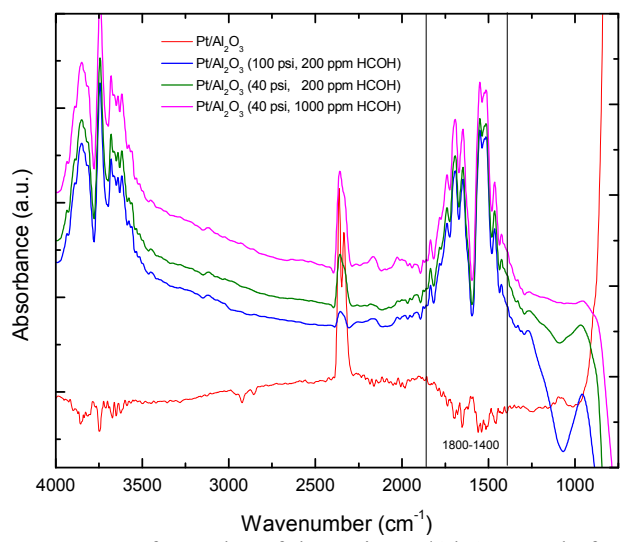

Fig. 9. FTIR spectra of samples of the series $\mathrm{Pt} / \mathrm{Al}_{2} \mathrm{O}_{3}$ tests before and after CWO reaction.

\section{2) Catalytic test for $\mathrm{Ce}-\mathrm{Mn}$}

Catalytic activity tests for the Ce-Mn catalyst were performed with an initial $200 \mathrm{ppm}$ formaldehyde concentration, at 40 psi oxygen pressure and $80^{\circ} \mathrm{C}$; only $60 \%$ $\mathrm{HCOH}$ conversion was obtained after four hours.

Fig. 10 shows the performance of the Ce-Mn during four hours; it can be seen that during the first minutes formaldehyde elimination produces only the formation of oxalic acid, but after two hours it begins to form acetic acid (less than $20 \mathrm{ppm}$ ) and other reaction products, such as carbonaceous deposits and/or $\mathrm{CO}_{2}$.

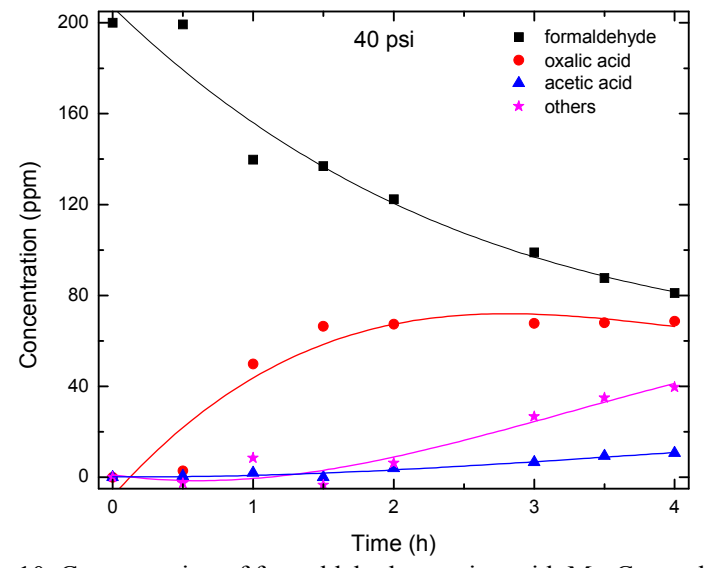

Fig. 10. Concentration of formaldehyde reaction with Mn-Ce catalyst.

The fact that greater oxalic acid content was observed may be due to an initial formaldehyde polymerization. The formation of low molecular weight carboxylic acids; this is a common step during the oxidation process, comprising refractory compounds difficult to oxidize, such as oxalic, acetic acid and formic acid, mainly [2].

The formation of carbonaceous deposits could only be corroborated by FTIR that also shows a considerable increase in the intensities of some bands coincident with the water vapor bands, but which may also be due to hydrogenated carbonate compounds formation or $\mathrm{CO}_{3}{ }^{2-}$ species (1440, 1530 and $1600 \mathrm{~cm}^{-1}$ ) [17] (see Fig. 11).

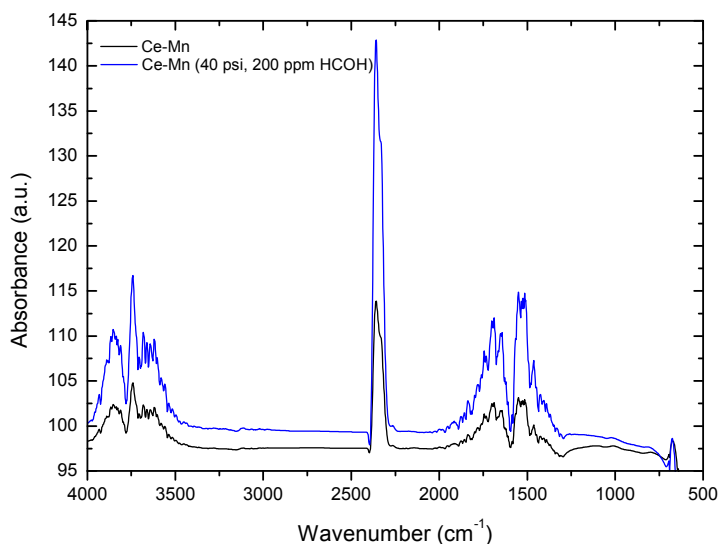

Fig. 11. IR spectra of samples of the Ce-Mn series before and after testing the CWO reaction.

Fig. 12 compares the reaction concentrations for both types of catalysts; it is clear that formaldehyde elimination occurs at faster and greater proportion when testing the Pt-based catalyst, due to the increased activity exhibited by the noble metal, which is in agreement with the results reported here and those reported by other authors [7], [9]. For both reaction tests, the oxalic acid concentration is similar, but that of the acetic acid changes significantly, having a lower formation percentage with the Ce-Mn system. In both cases it appears that during the first 90 minutes reaction, there is practically no formation of other products $\left(\mathrm{CO}_{2}\right.$ and carbonaceous deposits, among others).

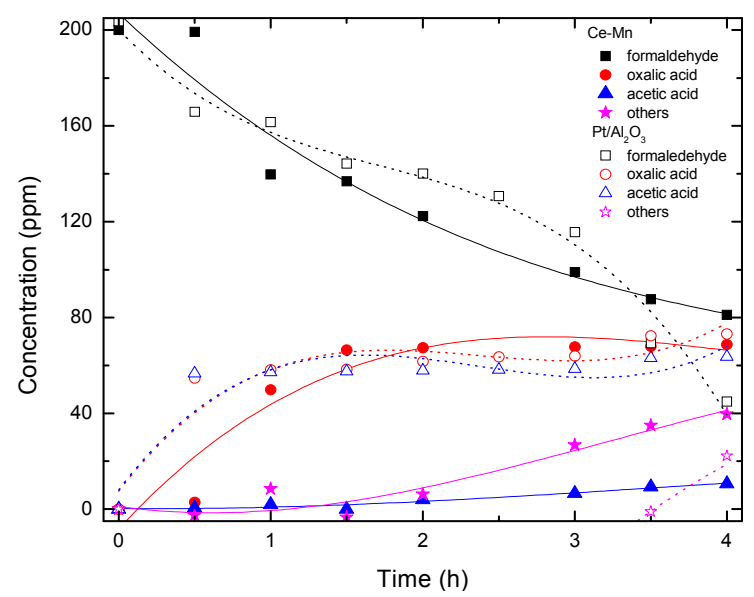

Fig. 12. CWO formaldehyde concentration profile vs time for catalys $\mathrm{Pt} / \mathrm{Al}_{2} \mathrm{O}_{3}$ and $\mathrm{Ce}-\mathrm{Mn}$.

\section{CONCLUSIONS}

The Ce-Mn catalyst displayed crystallographic structure characteristic of fluorite as revealed by the XRD results. The 
specific area value is in the range of like materials compared to those reported in the literature. The incipient wet impregnation method permitted the deposition of platinum on alumina according to the results XRD and SEM-EDS, which imparted the catalysts good activity for formaldehyde elimination.

The catalytic activity tests at $80^{\circ} \mathrm{C}$ temperature produced $80 \%$ elimination of formaldehyde with Pt-based catalyst for the CWO, which turned out to be more effective in removing the pollutant compared with the mixed oxide. Increasing the oxidizing agent pressure permitted greater formaldehyde elimination. Byproducts formation such as acetic and oxalic acids was determined along with carbonaceous deposits.

\section{ACKNOWLEDGMENTS}

The authors wish to express their thanks to students Isis Lesly Hernández, Guadalupe Garcia and Yazmin Gil. Also, GM gratefully acknowledges to the PROMEP program and GM, MV, TM and RM gratefully thank the SNI for the distinction of their membership and the stipend received.

\section{REFERENCES}

[1] J. Levec and A. Pintar, "Catalytic wet-air oxidation processes: A review," Catal. Today, vol. 124, pp. 172-184, June 2007.

[2] A. Silva, I. Castelo-Branco, R. Quinta-Ferreira, and J. Levec, "Catalytic studies in wet oxidation of effluents from formaldehyde industry," Chem. Eng. Sci., vol. 58, pp. 963-970, February 2003.

[3] M. Gutiérrez, "Development of catalytic membranes for phenol elimination in aqueous streams," Ph.D. dissertation, Dept. Chemical \& Environmental Engineering, University of Zaragoza, Zaragoza, Spain, 2007.

[4] C. Bozo, N. Guilhaume, and J. M. Herrmann, "Role of the ceria-zirconia support in the reactivity of platinum and palladium catalysts for methane total oxidation under lean conditions," J. Catal., vol. 203, pp. 393-406, October 2001

[5] J. J. Delgado, "Preparation and characterization of Ce-Mn and Ce- $\mathrm{Zr}$ oxides. Application in the wet oxidation of phenol," Ph.D. dissertation, Dept. Materials Science and Metallurgical Engineering and Inorganic Chemistry, Faculty of Science, University of Cádiz, Puerto Real (Cádiz), Spain, 2003.

[6] S. Hamoudi, F. Larachi, G. Cerrella, and M. Cassanello, "Wet oxidation of phenol catalyzed by unprompted and platinum-promoted manganese/cerium oxide," Ind. Eng. Chem. Res., vol. 37, pp. 3561-3566, August 1998.

[7] D. Lee and D. Kim, "Catalytic wet air oxidation of carboxylic acids at atmospheric pressure," Catal. Today, vol. 63, pp. 249-255, December 2000.

[8] A. Silva, R. Quinta-Ferreira, and J. Levec, "Catalytic and noncatalytic wet oxidation of formaldehyde. A novel kinetic model," Ind. Eng. Chem. Res., vol. 42, pp. 5099-5108, September 2003.

[9] J. Qin, Q. Zhang, and K. T. Chuang, "Catalytic wet oxidation of p-chlorophenol over supported noble metal catalysts," Appl. Catal. B: Environ., vol. 29, pp. 115-123, January 2001.

[10] X. Tang, J. Chen, X. Huang, Y. Xu, and W. Shen, "Pt/MnO $\mathrm{M}_{x}-\mathrm{CeO}_{2}$ catalysts for the complete oxidation of formaldehyde at ambient temperature," Appl. Catal. B: Environ., vol. 81, pp. 115-121, May 2008.

[11] M. Machida, M. Uto, D. Kurogi, and T. Kijima, " $\mathrm{MnO}_{x}-\mathrm{CeO}_{2}$ binary oxides for catalytic $\mathrm{NO}_{x}$ sorption at low temperatures. Sorptive removal of $\mathrm{NO}_{x}, "$ Chem. Mater., vol. 12, pp. 3158-3164, September 2000.

[12] S. Hamoudi, F. Larachi, A. Adnot, and A. Sayari, "Characterization of spent $\mathrm{MnO}_{2} / \mathrm{CeO}_{2}$ wet oxidation catalyst by TPO-MS, XPS, and S-SIMS," J. Catal., vol. 185, pp. 333-344, July 1999.

[13] S. Hamoudi, A. Sayari, K. Belkacemi, L. Bonneviot, and F. Larachi, "Catalytic wet oxidation of phenol over $\mathrm{Pt}_{x} \mathrm{Ag}_{1-x} \mathrm{MnO}_{2} / \mathrm{CeO}_{2}$ catalysts," Catal. Today, vol. 62, pp. 379-388, December 2000.

[14] H. Chen, A. Sayari, A. Adnot, and F. Larachi, "Composition-activity effects of $\mathrm{Mn}-\mathrm{Ce}-\mathrm{O}$ composites on phenol catalytic wet oxidation," Appl. Catal. B: Environ., vol. 32, pp. 195-204, August 2001.

[15] J. J. Delgado, J. A. Pérez-Omil, J. M. Rodríguez-Izquierdo, and M. A. Cauqui, "The role of the carbonaceous deposits in the catalytic wet oxidation (CWO) of phenol," Catal. Com., vol. 7, pp. 639-643, September 2006.

[16] M. Abecassis-Wolfovich, R. Jothiramalingam, M. V. Landau, M. Herskowitz, B. Viswsanathan, and T. K. Varadarajan, "Cerium incorporated ordered manganese oxide OMS-2 materials: Improved catalysts for wet oxidation of phenol compounds," Appl. Catal. B. Environ., vol. 59, pp. 91-98, March 2005.

[17] J. Miculová, J. Barbier, S. Rossignol, D. Mesnard, D. Duprez, and C. Kappenstein, "Wet air oxidation of acetic acid over platinum catalysts supported on cerium-based materials: Influence of metal and oxide crystallite size," J. Catal., vol. 251, pp. 172-181, October 2007.

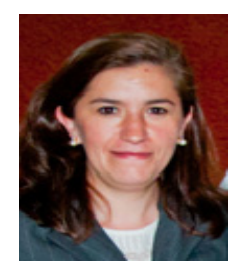

Mirella Gutiérrez-Arzaluz is an Mexican. She was born in Estado de México. She got her Ph.D. degree from the University of Zaragoza with the doctoral program in engineering and environmental chemistry, with distinction of quality, Zaragoza University, Zaragoza, Spain, in 2007. She got her master degree in science (chemical engineering) from Universidad Iberoamericana, Mexico in 2000 and the chemical engineering degree is from Universidad Autónoma Metropolitana, Mexico, in 1995 .

She is a research professor in Universidad Autónoma Metropolitana Azcapotzalco, México. She published an article "Preparation and characterization of $\mathrm{Ce}-\mathrm{Zr}$ and $\mathrm{Ce}-\mathrm{Mn}$ based oxides for n-hexane combustion: Application to catalytic membrane reactors," Chemical Engineering Journal, etc. Her research topic is environmental catalysis.

Ms. Gutiérrez is a member of the Academic Body and a member of the Mexican Association of Catalysis (ACAT). She is a member of the National System of Researchers (SNI) at level I, which is a distinction that awards for Mexican researchers.

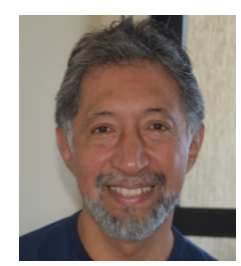

Miguel Torres-Rodríguez was born in Mexico city. He is a chemical engineering and received his master degree from the National Polytechnic Institute and his $\mathrm{PhD}$ in process engineering in 1993 from Claude Bernard University in Lyon France. He is a full time professor in the Universidad Autonoma Metropolitana Azcapotzalco in México. His research interests are the synthesis, characterization and application of materials in environmental catalysis. He has been a visitor professor during his sabatic periods in the Institute de Recherches sur la Catalyse in Lyon France in 2006 and in the Universidad Federal do Rio Grande do Norte, Brazil in 2011. Dr. Torres is a member of (Mexican Academy of Catalysis), ACAT and a member of the Mexican Membrane society.

Dr. Torres is an author of more than 30 papers published in indexed journals related to materials applied to the environment as well as related to environmental quality. He is a member of the National System od Researchers (SNI) at level two.

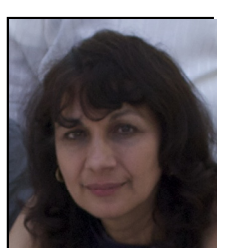

Violeta Mugica-Alvarez was born in Mexico City. She is a chemist for the Universidad Nacional Autónoma de México (UNAM). She has a master degree and a $\mathrm{PhD}$ in environmental engineering also from the UNAM

She is a full time professor at the Universidad Autónoma Metropolitana in México and is the coordinator of the master in science and environmental

engineering

Dr. Mugica has carried out researchs related to air and soil pollution, and related to the control and prevention of environmental pollution and emission of greenhouse gases. She is the author of more than 40 papers published in International Journals, several book chapters in the field of Environmental Sciences, mainly in air soil pollution. She has participated in more than one hundred national and international conferences.

Dr. Mugica has been a consultant of the Environment Ministry and of the United Nation Development Program for the assessment of the Actions to prevent air pollution in Mexico City and for the assessment of adaptation actions to face Climatic Change. She is a member of the National Academic of Sciences. She is the head of the Academic Body "Nanotechnology and Environmental Quality" in PROMEP program. She is a member of the 
National System of Researchers (SNI) at level II, which is a distinction that awards for Mexican researchers.

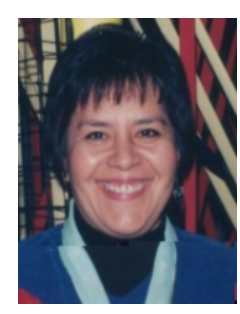

Julia Aguilar Pliego was bornin Mexico City. She is a chemist from the Universidad Nacional Autónoma de México UNAM. She has a master degree in chemist from the Universidad Metropolitana-Iztapalapa and a $\mathrm{PhD}$ from the Universidad Autónoma de Madrid.

She is a full time professor at the Universidad Autónoma Metropolitana. Her research interests are the synthesis, characterization and application of acidic materials for adsorption and environmental catalysts. She has published around 25 papers peer reviewed. And she has been the advisor of ten graduate theses.

Now is the vice-president of the Mexican Academy of Catalysis and the next elected President. She belongs to the Academic Body "Nanotechnology and Environmental Quality" in PROMEP program. She is a member of the
National System of Researchers (SNI) at level II, which is a distinction that awards for Mexican researchers.

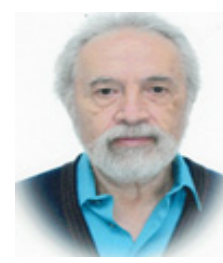

Mario A. Romero-Romo was born in Mexico City. $\mathrm{He}$ is an metallurgic chemical engineer from the Universidad Autónoma de México (UNAM) and received his $\mathrm{PhD}$ from the University of Liverpool, UK. He is a full time professor at the Universidad Autonoma Metropolitana Azcapotzalco in México. His research interests include corrosion engineering, electrochemistry and materials applied to the environment. Dr. Romero is a member of the Mexican Electrochemical Society and of the International Society of Electrochemistry.

Dr. Romero is an author of more than 100 papers published in indexed journals and has been the advisor of ten graduate thesis. He is a member of the National System od Researchers (SNI) at level two. 